\title{
Clinical presentations of urolithiasis: a prospective study in Referral Centre
}

\author{
Gaurav Rai Sharma, Sankalp Dwivedi, Bhavna Bhatia, Parul Kansal, \\ Avneet Kaur, Atul Rai Sharma, Pardeep Goyal, Ridhika Sharma
}

\begin{abstract}
Background: Urinary calculi are commonly diagnosed as a consequence of an episode of renalureteral colic or gross hematuria. Clinical manifestations are characterized by lumbar pain of sudden onset that may be accompanied by nausea and vomiting, gross or microscopic hematuria.

Objectives: To study clinical trends of urolithiais in the rural population.

Material and methods: The present prospective randomized study was conducted on 80 patients with clinically and radiologicaly suspected cases with urinary calculi in the department of Surgery, Maharishi Markandeshwar Institute of Medical Sciences and Research Mullana-Ambala during the period of two years (Oct 2010- Sep 2012). All the cases with urinary calculi were admitted. Detailed history including present complaints were taken. General physical examination as well as systemic examination was done in all the cases. Investigations including routine as well as special investigations were performed and all the cases were managed according to preset proforma. All the data obtained was recorded and analysed according to the preset proforma.

Results: Majority of patients in present study were admitted with the complaint of pain (96.3\%), burning micturition (85\%) and fever (77.5\%). 30\% patients had gross haematuria and around $11.25 \%$ of patients were admitted as acute retention of urine. All patients in present study when physically examined had shown the tenderness of varying severity according to the location and site of the Urinary calculi. In majority (41.3\%) tenderness was present in Rt flank/ iliac fossa. Suprapubic tenderness was present in only $12.5 \%$ of cases.

Conclusion: These patients mostly present with acute episodes of pain and burning micturition. Haematuria is less common way of presentation here. This study was an attempt to highlight the prevalence of urolithiasis in this belt and warrants the more exhaustive research in this regards.
\end{abstract}

\section{Introduction}

Stone formation is usually a result of urinary super saturation. Decreased fluid intake and consequent urine concentration are among the most important factors influencing stone formation. The hot arid areas, diet, physical activity and corporeal overweight could be other reasons. ${ }^{1,2}$ The most important principle of metaphylaxis of stones is decreasing the concentration of litho-genetic substances in the urine and increasing the urinary excretion of inhibitors of urinary stone formation. Any variation in urine saturation grade, urine $\mathrm{pH}$ and the concentration of crystallization inhibitors can break the normal existing balance and lead to urolithiasis. ${ }^{3}$

Urinary calculi are commonly diagnosed as a consequence of an episode of renal-ureteral colic or gross hematuria. ${ }^{4}$ Clinical manifestations are characterized by lumbar pain of sudden onset that may be accompanied by nausea and vomiting, gross or microscopic hematuria. ${ }^{2}$ Concomitant with the increasing prevalence of urolithiasis is the growing utilization of imaging for diagnosis, treatment planning, and post treatment follow-up. Material and methods: The present prospective randomized study was conducted on 80 patients with clinically and radiologically suspected cases with urinary calculi in the department of Surgery, Maharishi Markandeshwar Institute of Medical Sciences and Research Mullana- Ambala during the period of two years (Oct 2010- Sep 2012). All the cases with urinary calculi were admitted. Detailed history including present complaints were taken. General physical examination as well as systemic examination was done in all the cases. Investigations including routine as well as special investigations were peformed and all the cases were managed according to preset proforma. All the data obtained was recorded and analysed according to preset proforma.

\section{Results}

The present study was a prospective randomized study consisted of 80 patients of clinically and radiologically evaluated cases with urinary calculi in the department of Surgery, Maharishi Markandeshwar Institute of Medical Sciences and Research Mullana- Ambala for the period of two years (oct 2010 to sept 2012). In this study an attempt has been made for the evaluation of clinical trends. 
Table 1: Distribution of presenting symptoms

\begin{tabular}{|l|l|l|l|}
\hline S.No & Symptom & No. of cases & Percent \\
\hline 1 & Pain & 77 & 96.3 \\
\hline 2 & Burning micturition & 68 & 85 \\
\hline 3 & Heamaturia & 24 & 30 \\
\hline 4 & Pyuria & 7 & 8.75 \\
\hline 5 & Urinary Retention & 9 & 11.25 \\
\hline 6 & Frequency & 25 & 35 \\
\hline 7 & Urgency & 8 & 10 \\
\hline 8 & Fever & 62 & 77.5 \\
\hline 9 & Chills & 21 & 26.5 \\
\hline 10 & Rigors & 18 & 22.5 \\
\hline
\end{tabular}

Majority of patients in present study were admitted with the complaint of pain $(96.3 \%)$ followed by burning micturition (85\%) and fever (77.5\%). 30\% of patients had gross haematuria and around $11.25 \%$ of patients were admitted as acute retention of urine.

Table 2: Distribution of presenting symptoms- Pain

\begin{tabular}{|l|l|l|}
\hline Location & No. of cases & Percent \\
\hline Radiation ( back, groin, loin) & 70 & 87.5 \\
\hline Unilateral Flank pain & 48 & 60.0 \\
\hline Bilateral Flank pain & 16 & 16.3 \\
\hline Unilateral Ureteric (Inguinal fossa pain) & 13 & 16.3 \\
\hline Bilateral Ureteric (Inguinal fossa pain) & 0 & 0 \\
\hline Suprapubic pain & 8 & 10.0 \\
\hline Total & 77 & $77(96.3)$ \\
\hline
\end{tabular}

Among all patients who presented with pain, majority $(87.5 \%)$ of them showed pain radiation to back, groin or loin. Most of them were having unilateral pattern $(60.0 \%)$ and only few cases presented as bilateral pain. Approximately $10 \%$ patients of vesical calculi presented with supra-pubic pain.

Table3: Mean and SD of Pulse, Systolic, Diastolic, RR and Temp.

\begin{tabular}{|l|l|l|l|l|l|}
\hline & Pulse/min & B.P Systolic & B.P Diastolic & RR /min & TEMP/ .F \\
\hline Mean & 82.0 & 130.0 & 84.8 & 21.3 & 96.5 \\
\hline SD & 6.8 & 12.3 & 10.5 & 1.6 & 10.0 \\
\hline
\end{tabular}

Table 4: Distribution of physical findings (sign) - site of Tenderness

\begin{tabular}{|c|c|c|c|c|}
\hline Site & No. of cases & Percent & Chi square $\left(\chi^{2}\right)$ & $\mathrm{P}$ value \\
\hline Tenderness B/L flank/ iliac fossa & 20 & 25 & \multirow{5}{*}{12.8} & \multirow{5}{*}{$.01 ; \mathrm{p}<0.05$} \\
\hline Tenderness LT flank/ iliac fossa & 17 & 21.3 & & \\
\hline Tenderness RT flank/ iliac fossa & 33 & 41.3 & & \\
\hline Suprapubic tenderness & 10 & 12.5 & & \\
\hline Total & 80 & 100 & & \\
\hline
\end{tabular}

All patients in present study when physically examined, showed tenderness of varying severity according to the location and site of the Urinary calculi. In majority (41.3\%) tenderness was present in Right flank/ iliac fossa. Suprapubic tenderness was present in only $12.5 \%$ of cases.

Table5 : Distribution of physical findings (sign) - severity of Tenderness

\begin{tabular}{|l|l|l|l|l|}
\hline Severity & No. of cases & Percent & Chi square $\left(\chi^{2}\right)$ & \multirow{2}{*}{ P value } \\
\cline { 1 - 3 } 0.48 & \multirow{2}{*}{0.79} \\
\cline { 1 - 3 } Moderate & 29 & 36.0 & & \\
\hline Severe & 27 & 34.0 & 30.0 & \\
\hline
\end{tabular}


Table 6: Distribution of physical findings (signs) other than tenderness

\begin{tabular}{|c|c|c|c|c|}
\hline Signs & No. of cases & Percent & Chi square $\left(\chi^{2}\right)$ & $\mathrm{P}$ value \\
\hline Abdomen distension & 2 & 2.5 & \multirow{6}{*}{48.9} & \multirow{6}{*}{$.00 ; \mathrm{p}<0.0$} \\
\hline Guarding & 23 & 28.8 & & \\
\hline Rigidity & 1 & 1.3 & & \\
\hline Ballottment & 33 & 41.3 & & \\
\hline Bimanual Palpation & 25 & 31.3 & & \\
\hline Renal Angle fullness & 24 & 30.0 & & \\
\hline
\end{tabular}

Apart from tenderness, among other physical findings, ballottement of kidney was noted in $41.3 \%$ whereas kidneys were bimanually palpable in $31.3 \%$ of cases. Renal angle fullness was noted in $30 \%$ of the cases, whereas abdominal distension was present only in $2.5 \%$ of cases.

\section{Discussion}

Majority of patients in present study were admitted with the complaint of pain $(96.3 \%)$. Pain was fixed dull aching in cases of renal calculi and was localized to back, lumbar region. Pain was intermittent and colicky in cases of ureteric calculi and radiating to groin. Suprapubic dull aching pain was commonly seen in cases of bladder calculi. Pain in urethra and tip of penis was felt in cases of urethral calculi. Clinical manifestation of urinary calculi are an episode of renal -ureteral colic or gross haematuria, lumbar pain of sudden origin may be accompanied by nausea and vomiting., ${ }^{4,5}$

In the present study, pain was the most common complaint noticed in $96.3 \%$ patients of urolithiasis which is in concurrence with the study conducted by Drach. According to Drach the physical examination is negative in acute stone episode except tenderness and rigidity over the region of calculus. He has further stated that hydronephrotic or pyonephrotic kidney may be palpable. ${ }^{6}$

In the study conducted by Sepahi MA the main clinical presentations were fever, pain, irritability, dysuria and haematuria which is also similar to the results obtained by the present study. ${ }^{7}$

In the study done by Ali SH, haematuria was present in $44.6 \%$ patients and pain in $28.4 \%$ patients which is not in concurrence with the present study. This could be due to the consanguinity which was recorded in $72 \%$ cases. $^{8}$

Spivacow FR et al showed that the renal colic was the most frequent presentation seen in $72 \%$ cases which is in concurrence with the present study. ${ }^{9}$

Safaei et al evaluated the clinical features and metabolic and anatomic risk factors of urolithiasis in children. In this study, a total of 84 children (35 girls and 49 boys) were treated for urolithiasis. The most common presentations were urinary tract infection, restlessness, and abdominal pain. ${ }^{10}$

\section{Conclusion}

These patients mostly presented with acute episodes of pain and burning micturition. Haematuria was less common way of presentation in the present study. This study was an attempt to highlight the prevalence of urolithiasis in this belt and warrants the more exhaustive research in this regard.

\section{References}

[1] Portis AJ, Sundaram CP. Diagnosis and Initial Management of Kidney Stones. Am Fam Physician. 2001;63(7):1329-39.

[2] Bartoletti R, Cai T, Mondaim N, Melone F, Travaglim F, Carini M. Epidemiology and risk factors in urolithiasis. Urol Int. 2007;79(1): 3-7.

[3] Karagülle O, Smorag U, Candir F, Jonas U, Gehrke A, Gundermann G et al. Clinical study on the effect of mineral waters containing bicarbonate on the risk of urinary stone formation in patients with multiple episodes of Ca Oxalate urolithiasis. World $\mathrm{J}$ Urol. 2007;25:315-23.

[4] Tiselius HG, Ackermann D, Alken P, Buck C, Conort P, Gallucci M; Guidelines on urolithiasis. Eur Urol. 2001;40(4):362-71.

[5] Bilic-Curcic Z: Urolithiasis and osteoporosis. Collegium Antropol. 2009;33(2):189-92.

[6] Drach GW. Urinary lithiasis; Etiology, diagnosis and medical management. In Walsh P, Retik A, Stamey, Vaughan D. Eds. Campbell's Urology, 1992;3(6): p 2085-2156.

[7] Sepahi MA, Heidari A, Shajari A; Clinical manifestations and aetiology of renal stones in children less than 14 years age. Saudi J Kidney Dis Transpl,2010 Jan;21(1):181-4.

[8] Shatha Hussain Ali, Usama Nihad Rifat; Aetiological and Clinical patterns of childhood urolithiasis in Iraq. Pediatric Nephrology11/2005;20(10):1453-7

[9] Spivacow et al. Clinical and metabolic risk factor evaluation in young adults with kidney stones. Int urol Nephrol.2010 Jun; 42(2):471-5.

[10] Safaei AA, Maleknejad S. Pediatric Urolithiasis: an experience of a single centre. Iran J of Kidney Dis. 2011;5(5):309-13. 